\title{
Gestão em Geoparques: Desafios e Realidades
}

\author{
Geoparks Management: Challenges and Realities
}

\author{
Administración de Geoparques: Retos y Realidades
}

\author{
Carlos Alberto Freire Medeiros ${ }^{1}$ \\ Cristiane Soares Cardoso Dantas Gomes ${ }^{2}$ \\ Marcos Antônio Leite do Nascimento ${ }^{3}$
}

\begin{abstract}
Resumo: Os geoparques representam parte de um conceito holístico de proteção, educação e desenvolvimento sustentável. Nesses espaços são valorizadas atrações turísticas locais com ênfase nos aspectos geológicos, maximizando o Geoturismo. Esta atividade traz benefícios econômicos locais e educam as pessoas sobre a evolução do seu local e paisagem. Por não estar atrelado a nenhuma lei, aos geoparques é permitido diferentes formas de gestão. Para compreender o gerenciamento desses espaços, objetivo deste trabalho, é apresentada uma análise detalhada dos planos de gestão de geoparques nacional e internacionais com a finalidade de compreender a administração desses territórios. A metodologia utilizada apesenta um enfoque qualitativo de caráter exploratório, posto que se observou a necessidade de apreender sobre a gestão de geoparques. Destarte, adotou-se uma pesquisa bibliográfica e documental, em que o instrumento de coleta de dados adotado foram os planos de gestão de geoparques nacional e internacionais. A análise desses documentos- planos de gestão- tornou possível identificar que não há um tipo de gestão padrão a esses locais e que administração desses espaços ocorre conforme a realidade de cada local. Entretanto, há pontos em comuns nos planos de gestão, em que o Geoparque Arouca (Portugual) é o que apresenta o contexto gerencial mais completo por utilizar mais das ferramentas da administração. Assim, a gestão dos geoparques se adapta aos seus diferentes contextos socioeconômicos, incorporando-os na esfera do planejamento.
\end{abstract}

Palavras-chave: Geoturismo. Geoparque. Gestão.

Abstract: The geoparks represent part of a holistic concept of protection, education and sustainable development. These spaces are valued local tourist attractions with emphasis on geological features, maximizing Geotourism. This activity brings local economic benefits and educate people about the evolution of your site and landscape. By not being tied to any law, the geoparks is allowed different forms of management. To understand the management of these spaces aim of this study is to present a detailed analysis of national and international geoparks management plans in order to understand the management of these territories. The methodology used apesenta a qualitative focus exploratory, since it noted the need to seize on geoparks management. Thus, it adopted a bibliographical and documentary research, in which the data collection instrument were adopted plans for national and international geoparks management. The analysis of these documents- plans gestões- made it possible to identify that there is a kind of standard management of these sites and that management of these areas occurs as the reality of each location.

1 Universidade Federal do Rio Grande do Norte- UFRN Bacharel em administração pela Universidade federal do Rio Grande do Norte (1990), Mestre em Administração (1997) pela UFRN e Doutorado em administração pela USP (2003). Professor Adjunto da UFRN. E-mail: Carlosalbertofreiremedeiros@gmail.com

2 Universidade Federal do Rio Grande do Norte- UFRN. Mestra em Turismo pela Universidade Federal do Rio Grande do Norte (2013). Pós- graduada em Direito e Processo do Trabalho pela Faculdade de Tecnologia Darcy Ribeiro e Graduada em Turismo pela Universidade Federal do Rio Grande do Norte (2007) E-mail: crisscdantas@gmail.com

3 Universidade Federal do Rio Grande do Norte- UFRN (2000) e doutorado (2003) em Geodinâmica e Geofísica pela UFRN. Professor Adjunto II do departamento de Geologia da UFRN. E-mail: Marcos@geologia.ufrn.br 
However there are points in common in the efforts made in the Arouca Geopark is the one with the most comprehensive managerial context to use more of the administration tools. Thus, the management of geoparks adapts to their different socio-economic contexts, incorporating them in the planning sphere.

Keywords: Geotourism. Geopark. Management.

Resumen: Los geoparques representan parte de un concepto integral de la protección, la educación y el desarrollo sostenible. Estos espacios se valoran las atracciones turísticas locales, con énfasis en las características geológicas, la maximización de Geoturismo. Esta actividad trae beneficios económicos locales y educar a la gente acerca de la evolución de su sitio y el paisaje. Al no estar atado a ninguna ley, los geoparques se permite diferentes formas de gestión. Para entender la gestión de estos espacios objetivo de este estudio es presentar un análisis detallado de los planes nacionales e internacionales de gestión de parques geológicos a fin de entender la gestión de estos territorios. La metodología utilizada apesenta un exploratoria enfoque cualitativo, ya que señaló la necesidad de aprovechar en la gestión de parques geológicos. Así, se adoptó una investigación bibliográfica y documental, en el que el instrumento de recolección de datos se adoptaron planes para la gestión de los parques geológicos nacionales e internacionales. El análisis de estos planes documentos- gestões- hicieron posible identificar que existe una clase de gestión estándar de estos sitios y que la gestión de estas áreas se presenta como la realidad de cada lugar. Sin embargo, hay puntos en común en los esfuerzos realizados en el Geoparque Arouca es el que tiene el contexto más amplio de gestión a utilizar más de las herramientas de administración. Por lo tanto, la gestión de los parques geológicos se adapta a sus diferentes contextos socioeconómicos, incorporándolos en la esfera de planificación.

Palabras Claves: Geoturismo. Gestión. Geoparque.

\section{GEOPARQUE E SUA RELAÇÃO COM O GEOTURISMO}

Geoparque é uma marca atribuída pela Rede Global de Geoparques sob os auspícios da UNESCO a uma área onde sítios do patrimônio geológico representam parte de um conceito holístico de proteção, educação e desenvolvimento sustentável. Um geoparque deve gerar atividade econômica, notadamente por intermédio do turismo, e envolve um número de sítios geológicos (ou geossítios) de importância científica, raridade ou beleza, incluindo formas de relevo e suas paisagens. Vale salientar que aspectos arqueológicos, ecológicos, históricos ou culturais podem representar também importantes componentes de um geoparque.

Sua origem foi fruto de uma reflexão que ocorreu em 1996 durante o 30 congresso internacional de geologia, em Pequim na China, em que Nicolas Zouros e Guy Martini preocupados em encontrar alguma forma e/ou recurso para promover a gestão sustentável do patrimônio geológico, tiveram a ideia de criar uma iniciativa que permitisse o desenvolvimento sustentável por meio da proteção e promoção do patrimônio geológico com a finalidade de desenvolver atividades científicas, educativas e turísticas. Com isso, essa estratégia seria também uma garantia para a conservação desses lugares de interesse geológico (Zouros, 2004).

Somente no ano de 2000, sob os auspícios da UNESCO, foi criada a Rede Europeia de Geoparques cujo objetivo é proteger a Geodiversidade (meio abiótico), para promover o Patrimônio Geológico para o público em geral, bem como para apoiar o desenvolvimento econômico sustentável dos territórios dos Geoparques, principalmente com base no turismo e na educação. A rede 
tem unificado os territórios de toda a Europa que compartilham estes objetivos e que estão agora a trabalhar juntos de uma forma ativa e dinâmica para atingi-los. ${ }^{4}$

O sucesso da Rede Europeia de Geoparques levou a UNESCO a envolver-se um pouco mais nesta nova dinâmica, sendo criado em 2004 a Rede Global de Geoparques. O objetivo da Rede Global é fornecer uma plataforma de cooperação e intercâmbio entre especialistas e profissionais em matéria de patrimônio geológico. Atualmente a rede conta com 111 Geoparques distribuídos em 32 países. Esta se estende por todas as regiões do mundo e reúne grupos que compartilham valores comuns, interesses ou fundos (Eder \& Patzak, 2004).

Os geoparques são espaços em que são valorizadas atrações turísticas locais com ênfase nos aspectos geológicos. Estes espaços estão sendo vistos como alternativas férteis para oportunidades de emprego, promoção de benefícios econômicos para as pessoas que vivem em suas áreas ou próximas a elas, por meio da criação de empresas locais e indústrias caseiras envolvidas no geoturismo e com seus geoprodutos. Segundo Farsani et al. (2010), os Geoparques são fatores chaves para o desenvolvimento do Geoturismo, uma vez que maximiza esta atividade, além de trazer benefícios econômicos locais e educam as pessoas sobre a evolução do seu local e paisagem.

Entretanto, vale uma ressalva para diferenciar um geoparque de uma área protegida, que a priori possuem aspectos diferentes. Apesar que muitas das unidades de conservação no Brasil têm no Patrimônio geológico seu principal atrativo, Nascimento; Ruchkys \&Mantesso Neto (2008, p. 23) mencionam que "o SNUC não aborda de forma específica o patrimônio geológico, quando o faz é de maneira simplista e superficial. " As unidades de conservação, no caso as de proteção integral, resulta na preservação da natureza admitindo apenas o uso indireto dos recursos, não sendo possível compatibilizar o desenvolvimento de atividades sustentáveis.

Os geoparques têm como premissa a inserção da comunidade no desenvolvimento de suas atividades, até porque, é um dos elementos que são avaliados pela UNESCO para sua inserção na rede. Além do mais, o conceito de Geoparque é dinâmico e tem a capacidade de se adequar as diferentes realidades locais e devido a isto, não há enquadramento em uma legislação específica, visto que a denominação "parque", conforme Boggiani (2010), gerou discussões sobre as relações com o SNUC- Sistema Nacional de Unidades de Conservação, lei que regula a criação de categorias de unidades de conservação no Brasil. Segundo Boggiani (2010, p.2) “Ao enquadrar o conceito de geoparque em uma lei específica, iríamos engessar o processo e tirar o caráter inovador e dinâmico que ele representa e o que o torna diferente de outras modalidades de conservação" O autor ainda menciona que:

O entendimento que se deve ter é a de que um geoparque não é uma unidade de conservação no sentido do SNUC e, por isso, não há necessidade de criação de categoria específica e nem uma legislação para geoparques no Brasil, da mesma forma que não é necessário para as reservas da biosfera, outra importante modalidade da UNESCO que também vem sendo implementada no Brasil em seus diferentes biomas. (BOGGIANNI 2010, p.1).

\footnotetext{
${ }^{4}$ Maiores informações disponível em http://www.europeangeoparks.org/.
} 
Para elucidar os diferentes aspectos entre geoparques e unidades de conservação, o quadro 1 a seguir ilustra as diferenças entre essas duas modalidades de áreas naturais:

Quadro 1- Principais diferenças entre áreas protegidas e geoparques

\begin{tabular}{|l|l|}
\hline \multicolumn{2}{|c|}{ Principais diferenças entre áreas protegidas e geoparques } \\
\hline Áreas protegidas & Geoparques \\
\hline $\begin{array}{l}\text { Em algumas modalidades há necessidade de } \\
\text { remoção dos moradores, bem como não uso do } \\
\text { local para fins de preservação. }\end{array}$ & $\begin{array}{l}\text { Inserção da comunidade nas atividades do geo- } \\
\text { parque, seja por meio de atividades que os mo- } \\
\text { radores já desenvolvem e/ou iniciativas empre- } \\
\text { endedoras. }\end{array}$ \\
\hline Foco na biodiversidade & $\begin{array}{l}\text { Foco na geodiversidade associada com a cultura, } \\
\text { turismo, interpretação ambiental, educação } \\
\text { científica. }\end{array}$ \\
\hline $\begin{array}{l}\text { Gestão do espaço de acordo com os princípios } \\
\text { do SNUC e obrigatoriedade de um Conselho } \\
\text { Gestor. }\end{array}$ & $\begin{array}{l}\text { Como não existe lei atrelada a questão gerenci- } \\
\text { al, possibilita várias formas de gestão. }\end{array}$ \\
\hline $\begin{array}{l}\text { Aborda o ecoturismo e atividades pautadas na } \\
\text { natureza }\end{array}$ & $\begin{array}{l}\text { Aborda o geoturismo e atividades que utilize a } \\
\text { geodiversidade como pano de fundo, sem inter- } \\
\text { vir em outras atividades turísticas. }\end{array}$ \\
\hline
\end{tabular}

Fonte: Elaboração própria (2015)

Essas diferenças permitem identificar as distinções de focos e abordagens entre as duas modalidades de áreas naturais. Há quem os identifiquem como semelhantes, entretanto é possível verificar divergências entre ambos.

Na concepção de um Geoparque, recomenda-se o geoturismo, apontado como uma atividade relevante para conservação dos aspectos geológicos e, portanto, esse tipo de turismo passa a ser reconhecido, difundido e valorizado. Newsome e Dowling (2010) definem o Geoturismo como "uma forma de turismo em áreas naturais que incide especificamente sobre a geologia e a paisagem". Ela promove o turismo em geossítios com a conservação da geodiversidade e uma compreensão das ciências da terra através da apreciação e aprendizagem. Isto é conseguido por meio de visitas independentes para características geológicas, uso de trilhas e ponto de vista, visitas guiadas, atividades e patrocínio de centros de categorias geológicas temáticas (Dowling, 2011).

O geoturismo desponta como uma atividade importante na conservação e valorização do patrimônio geológico, que faz parte do patrimônio natural. Conforme Dowling (2011), esta atividade está emergindo como um novo fenômeno global. Atividade turística que enfatiza as feições geológicas e as tem como seu principal atrativo. Essa atividade permite um novo olhar à visitação turística, não tornando esta meramente contemplativa, mas, vindo a permitir o entendimento dos locais visitados, resultando na compreensão e importância daqueles aspectos geológicos, promovendo sua conservação.

Por mais que o geoturismo enfoque os aspectos geológicos, o mesmo tem ligação com outras formas de turismo como o ecoturismo, turismo de aventura, turismo cultural. A Figura 1 ilustra a ligação do geoturismo com as demais formas de turismo, onde as linhas contínuas e tracejadas representam as vias de interligação. A conexão entre ecoturismo e geoturismo é representada como uma relação particularmente forte. 
Figura 1 - Relação do geoturismo com outras formas de turismo

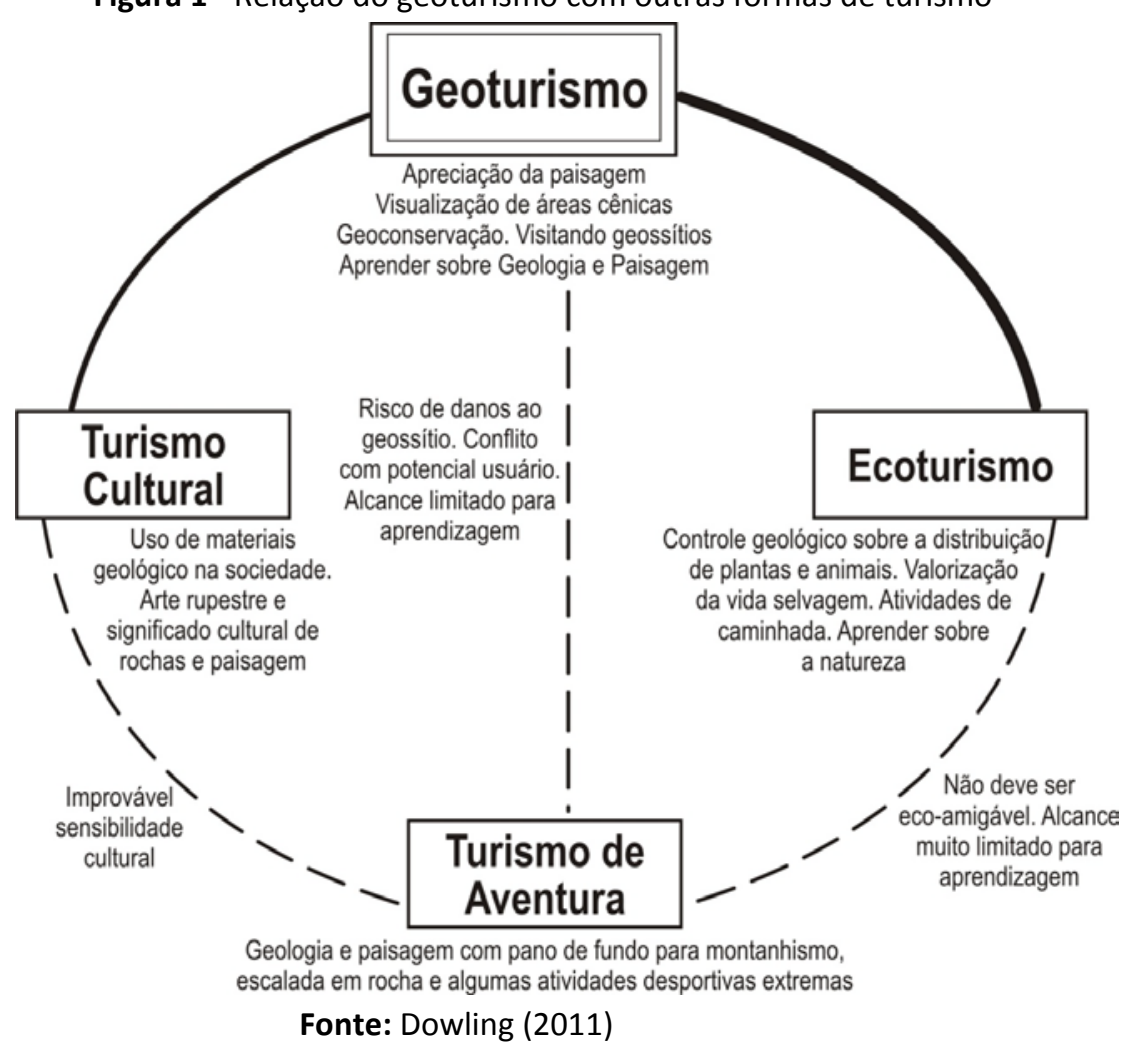

A prática do geoturismo por fazer uso das formas de relevo, paisagens, minerais, rochas e fósseis, articula-se com outras atividades, como é o caso do ecoturismo. Apesar desta atividade evidenciar a fauna e a flora e focar na proteção e conservação de tais elementos, o meio físico (meio abiótico), que condiciona o tipo de vegetação que irá se desenvolver naquele local e consequentemente, a fauna predominante, muitas vezes é negligenciado.

O geoturismo se concatena com o turismo de aventura por este último utilizar as rochas e o relevo para sua prática, porém sem o menor conhecimento a cerca destes elementos da geodiversidade. Em relação a conexão entre o turismo cultural e geoturismo, é que ambos se utilizam de materiais geológicos, sob a forma de artes rupestres ou diferentes utensílios fabricados com minerais e rochas, para explicar a gênese de um local e reforçar a cultura de uma localidade. Assim, as práticas citadas anteriormente se correlacionam com o geoturismo por utilizar da geodiversidade, paisagem e cultura como pano de fundo para suas atividades.

Dessa maneira, o geoturismo é uma forma sinérgica de turismo, onde os elementos da paisagem e as formas de relevo, juntos, criam uma experiência turística que é mais rica do que a soma das partes. A atividade proporciona benefícios econômicos para a população local, além de ter um grande papel no desenvolvimento regional. O seu desenvolvimento representa uma parceria entre a população local, o setor privado e o governo. O progresso dessa atividade pode oferecer aos moradores locais geração de emprego e renda, bem como o desenvolvimento de competências. 
Nesse sentido, os geoparques aparecem como espaços que oportunizam o geoturismo, onde aqueles são considerados fatores chaves para o desenvolvimento da atividade. Além do mais, podem contribuir diretamente para o desenvolvimento econômico das comunidades, seja por meio de pequenas e médias empresas que desenvolvam produtos e serviços, como a fabricação de uma lembrança associada a algum elemento do Geoparque, atividades relacionadas com lazer, como: ciclismo, escalada, atividades culturais, artísticas dentre outras.

Para que o Geoparque atinja sua eficiência e eficácia é importante o engajamento de todos que possam colaborar com seu planejamento, desenvolvimento, inovação, divulgação e promoção. Por isso a importância de atividades inovadoras, a realização de consultorias com empresários locais com a finalidade de explicar a importância econômica e social que os geoparques podem gerar, bem como estimular parcerias com artistas locais, operadoras de turismo, setores privados, meios de hospedagem, restaurantes, além do envolvimento dos moradores para que possam contribuir com a conservação do local e promoverem atividades educacionais, gerando os benefícios que realmente se espera com um Geoparque. Essa interação pode ser visualizada como uma rede de atividades que podem acontecer em um Geoparque.

\section{METODOLOGIA}

Para atingir a finalidade da pesquisa, recorreu-se ao site da Rede Global de Geoparques e da UNESCO, no qual estão cadastrados os geoparques que fazem parte da Rede Global com seus respectivos e-mails. Destarte, foram escolhidos uma amostra aleatória de 30 geoparque dos 92 que estavam registrados na época. Desse universo de 30 geoparques, foram enviados e-mails a todos, entretanto, obteve-se resposta de apenas 5 geoparques; Geoparque Arouca (Portugal), Geoparque English Riviera (Reino Unido), Geoparque Stonehammer (Canadá), Geoparque Kanawinka (Austrália) e o Geoparque Araripe (Brasil).

O conteúdo do e-mail era a solicitação dos planos de gestão dos respectivos geoparques para fins de análise do gerenciamento desses espaços e pontos de convergências entre os referidos planos. Logo, a pesquisa apesenta um enfoque qualitativo de caráter exploratório, posto que se observou a necessidade de apreender sobre a gestão de geoparques para a aplicação, em uma situação futura, no gerenciamento de geoparques no Brasil. Destarte, adotou-se uma pesquisa bibliográfica e documental, em que o método para levantamento dos dados é a coleta de documentos de primeira ou segunda mão. $O$ instrumento de coleta de dados adotado foram os planos de gestão de geoparques nacional e internacionais, portanto, documento de primeira mão. A análise desses documentos- planos de gestão- tornou possível identificar que não há um tipo de gestão padrão a esses locais e que administração desses espaços ocorre conforme a realidade de cada local, de acordo com que está exposto nos tópicos seguintes. 


\section{GESTÃO DE GEOPARQUES}

Uma característica do geoparque é sua capacidade de agregação e articulação institucional, visto que não está atrelada a nenhuma lei, como mencionado anteriormente, permitindo uma ampla gama de formas de gestão, podendo ser até privado. Além do mais, outra vantagem de um geoparque é a possibilidade de criação de forma aberta sem rigidez jurídica.

A articulação gerencial desses espaços está vinculada as características locais do território ao qual está inserido. A flexibilidade jurídica quanto à criação desses espaços permite um planejamento que possa inserir tanto a comunidade, empresários locais, instâncias de gestão local e o meio acadêmico. Como não existe uma uniformidade para o gerenciamento desses espaços, e como uma forma de melhor compreender essa dinâmica gerencial, foram solicitados planos de geoparques nacional e internacionais para entender melhor o funcionamento desses espaços. Abaixo, seguem as análises dos referidos planos de gestão obtidos.

\subsection{Gestão do Geoparque Arouca (Portugal)}

O plano de gestão do Geoparque Arouca foi fundamentado em um planejamento estratégico traçado entre os anos de 2008 a 2013. Neste plano a AGA - Associação Geoparque Arouca que gere o território, é uma associação de direito privado sem fins lucrativos criada por uma escritura pública em 9 de junho de 2008.

A associação tem como objetivo promover e realizar ações direcionadas a um desenvolvimento socioeconômico, cultural, ambiental, sustentável e equilibrado do conselho de Arouca e da região, nomeadamente através da gestão da área classificada de "Geoparque". Outro objetivo é a conservação, promoção e valorização do seu patrimônio cultural, natural e geológico; promoção de um turismo sustentável, além de potencializar o desenvolvimento de atividades econômicas locais e fomentar as atividades tradicionais, bem como promover e desenvolver formação profissional. (Plano Estratégico 2008-2013 Geoparque Arouca, p.2). Além dos objetivos citados, a AGA promove e realiza ações de sensibilização ambiental e de animação cultural e turística, procede a recolha, tratamento e divulgação de informações sobre os recursos da região, realizam ações de proteção, conservação e divulgação do patrimônio cultural, com especial ênfase no patrimônio geológico, realiza ações de cooperação com outras entidades que possam contribuir para a realização dos objetivos da associação. Além do mais, a associação comercializa o artesanato regional, produtos locais e outros.

A composição da Associação Geoparque Arouca é formada por uma Assembleia Geral que integra 18 associados (sendo 7 entidades de natureza pública e 11 de natureza privada), uma direção composta por 5 entidades (duas públicas e três privadas), presidida pela Câmara Municipal de Arouca, e o Conselho Fiscal composto por uma entidade pública e duas privadas. A AGA também conta com um conselho científico com especialistas em conhecimentos em geologia, ciências da terra e geociências. 
A equipe técnica da AGA é composta de um Coordenador Executivo com formação na área de economia e gestão, um Técnico superior em geologia com mestrado na mesma área, um Técnico superior em Turismo com formação em gestão e planejamento turístico, um Técnico de marketing e comunicação, uma pessoa responsável pela parte administrativo financeira e um responsável pela parte contábil.

O plano estratégico do Geoparque Arouca traz uma Análise SWOT que de acordo com Ghemawat (Perinotto, 2009) o objetivo desse tipo de análise (SWOT - Strengths, Weaknesses, Opportunities and Threats - pontos fortes, pontos fracos, oportunidades e riscos/ ameaças) é definir estratégias para manter os pontos fortes, reduzir a intensidade de pontos fracos, aproveitando as oportunidades e se protegendo dos riscos. Dessa forma, mediante a predominância de pontos fortes ou fracos e de oportunidades ou riscos, podem ser adotadas determinadas estratégias que busquem a manutenção, crescimento ou desenvolvimento de uma organização ou localidade.

A análise SWOT aborda pontos importantes em um planejamento e o Geoparque Arouca aborda essa ferramenta em seu plano, apresentando uma descrição geral de quais são os pontos fortes, fracos, oportunidades e ameaças. Este plano abrange uma abordagem mais detalhada com relação a análise SWOT de cada segmento que se encontra na área do geoparque como: Acessibilidade, Recursos Naturais, Artesanato, Gastronomia, Turismo, Ambiente/Qualidade de vida, Agricultura, flores e pecuária, Desenvolvimento social, População, Educação/Formação, Empregabilidade, Empreendedorismo/Criação de novas empresas, Indústria/Serviços, Comércio local e Associativismo enquanto desenvolvimento Territorial.

O plano de gestão deste geoparque aborda o cenário econômico da área, retrata a importância do Geoturismo para o local, além de trazer mais uma ferramenta da administração que é uma matriz de enquadramento lógico, que segundo Schiefer (2006) é um instrumento de planejamento fundamental que condensa os diferentes aspectos de um projeto numa única matriz, em que permite distinguir objetivos globais e específicos, estabelece os indicadores de sucesso, entre outros. Esta estruturação permite, ainda, verificar se a intervenção é corretamente instruída, facilita o acompanhamento da intervenção e proporciona uma avaliação mais satisfatória.

Este geoparque teve a preocupação em seu plano de mostra quais as ações a serem realizadas, os níveis de prioridades, cronogramas e os responsáveis a executarem as ações, além de apresentar uma estratégia de marketing e comunicação com o objetivo de organizar, posicionar e direcionar os serviços, os produtos e a marca "Geoparque Arouca", além de contribuir para a promoção de ações fundamentais para valorizar, proteger e dinamizar o território Geoparque Arouca.

Outro ponto relevante foi a preocupação de mostrar a segmentação de mercado potencial e uma análise de concorrência. A AGA ressalta a importância de métodos de avaliação e controle a ser desenvolvido antes, durante e depois das ações de marketing, permitindo reduzir as diferenças entre o desempenho esperado e o real, garantindo sua eficácia em uma perspectiva contínua. 


\subsection{Gestão do Geoparque English Riviera (Reino Unido)}

A gestão deste geoparque gira em torno da organização ERGO-Geoparque Riviera que está atrelada a grupos de trabalhos como o de recursos naturais, responsável pela proteção oficial dos locais; a Universidade de Plymouth; South Devon College e as escolas locais que ficam responsáveis pela investigação e pesquisa; Torbay Businnes fórum responsável pelo envolvimento do setor privado; o grupo Devon RIGS responsável pelo conhecimento geológico do local; e o grupo Torbay Heritage fórum responsável pela interpretação, educação, eventos e vistas. O conselho de Torbay fica responsável pelo serviço de transporte, serviço cultural, parcerias com museus e serviços para crianças. Já a agência de desenvolvimento de Torbay zela pela parte de turismo, marketing e desenvolvimento econômico e finalmente a Torbay Coast \& Countryside Trust que responde pela gestão dos geossítios.

O objetivo da gestão deste geoparque está reunido em três temas primordiais e estes determinam o programa de trabalho da gestão do Geoparque Riviera. Um desses temas é a questão das redes de gestão que tem a finalidade de manter a ERGO e coordenar as atividades, garantir que os geossítios ou locais que tenham ligação com patrimônio geológico estejam no topo da agenda a fim de enfatizar o desenvolvimento sustentável e trabalhar dentro da Rede Europeia de Geoparques com o intuito de promover a construção de redes e parceiros com outros geossítios europeus e mundiais. O segundo tema seria a conservação dos locais pelo fato de facilitar, proteger e valorizar os geossítios, além de incentivar a investigação sobre métodos para uma gestão sustentável e melhores práticas para compartilhar com outros geossítios do Reino Unido ou do exterior (Plano de Gestão do English Riviera Geopark, 2009).

O terceiro tema é a Geoeducação e o Geoturismo. O turismo é uma atividade econômica importante em Tobay (área que abrange o geoparque), que emprega direta e indiretamente 15.000 pessoas, correspondendo a $13,5 \%$ do PIB do local. Atrelando o potencial da atividade com os aspectos geológicos do local, o plano é pautado na temática da geoeducação e geoturismo com o intuito de promover ativamente o desenvolvimento econômico através da valorização das atividades de turismo ligadas ao patrimônio geológico, além de incentivar e permitir o acesso aos geossítios, onde pode ser alcançado de forma sustentável para o benefício da comunidade e desenvolver programas de interpretação relativos aos geossítios.

O plano de gestão deste geoparque atrela ferramentas da administração, a análise SWOT ao patrimônio geológico, para tanto a análise dos pontos fortes, pontos fracos, oportunidades e ameaças são em cima do patrimônio geológico do local. Além da análise SWOT, o geoparque conta com um plano de ação detalhando todas as ações, os responsáveis por estas e o tempo para o alcance do objetivo, seja ele de curto, médio ou longo prazo. 


\subsection{Gestão do Geoparque Stonehammer (Canadá)}

O plano de gestão deste geoparque foi desenvolvido cuidadosamente sobre a perspectiva da gestão compartilhada. O mesmo foi elaborado com ampla participação de muitas organizações, comunidades, indivíduos e especialistas de diversas áreas. As ações que constam no plano servem de base sólida para a realização dessa visão.

Segundo o plano de gestão deste geoparque, em razão do mesmo possuir mais de 60 geossítios e muitos destes localizam-se em áreas de propriedade pública e privada, a operação eficaz para o funcionamento da área só poderia ser realizada por meio do modelo de parceria. O modelo que consta no plano de gestão do mesmo foi projetado para aproveitar os recursos de muitos parceiros, mas esses 60 geossítios são operados e governados por uma única unidade ligada ao Geoparque Stonehammer.

O modelo de parceria acontece de duas maneiras que estão aptas a operar no geoparque. Existem os proprietários do lugar e os usuários do lugar. As organizações parceiras que tem controle sobre os geossítios (os proprietários) operam por meio de um memorando de entendimento, que é um acordo para atender aos padrões estabelecidos pelo Geoparque Stonehammer sobre a manutenção dos geossítios, interpretação geológica, geoturismo e preservação. Cada geossítio tem sua gestão e seu plano operacional, mas estes estão alinhados com as normas estabelecidas pelo geoparque. Em troca, essas organizações podem usar os recursos do Geoparque para promover os objetivos do seu geossítio.

Já os usuários dos locais que o utilizam para educação e o geoturismo, operam o local também por meio de um memorando de entendimento que define sua participação. Essas organizações que usam os geossítios podem utilizar os recursos dos geoparques para desenvolver suas atividades. A autoridade do geoparque vai trabalhar com os parceiros para que sejam garantidas as regras relativas a proteção geológica, se a questão da interpretação atende os padrões científicos, além de verificarem se o geoturismo é conduzido de forma sustentável e responsável.

O geoparque conta com um Conselho de Administração composto por 10 membros voluntários, sendo quatro a serem designados e cinco membros eleitos e um especialista em geologia selecionado pelo conselho. O Conselho de Administração contempla um Comitê Executivo com mandato de dois anos composto por um Presidente, um Vice- Presidente, um Tesoureiro.

O Conselho de Administração possui comissões de trabalho como de finanças e administração, que supervisionam as operações financeiras do geoparque; comitê de planejamento estratégico, responsável por todo planejamento estratégico da organização; comitê de Educação e Preservação, responsável por assegurar a preservação e manejo no geoparque, incluindo atividades de conscientização e educação; comitê de conexões comunitárias, responsável por promover a participação ativa das comunidades, assegurando o envolvimento da mesma na operação de desenvolvimento sustentável.

Além dos mencionados acima, o conselho de Administração conta com outros conselhos como o de Marketing e Desenvolvimento Econômico, que desenvolve e coordena as iniciativas de 
marketing do geoparque e garante que os membros estão aderindo aos padrões da marca. Há o comitê corporativo, composta de grandes patrocinadores; o comitê de conexões culturais, que trabalha para promover e impulsionar a cultura, artes, o patrimônio e a história. O conselho possui um grupo de assessoria técnica, que realiza uma revisão anual das operações do geoparque e que garante que estes sejam fiéis aos princípios fundamentais da autenticidade e precisão.

Embora cada local seja operado independentemente, todos os locais são membros do Geopark Stonehammer e seguem suas orientações e padrões para o seu funcionamento. O plano possui um cronograma de ações, mencionando como se encontra o andamento das ações, se estão completas, em andamento, as responsabilidades de cada um e a data limite para suas execuções.

\subsection{Gestão do Geoparque Kanawinka (Austrália)}

O plano de gestão obtido deste geoparque apresentou orientações de como ocorreu sua gestão nos anos de 2010 a 2012, em que estabeleceram as considerações, resultados, estratégias que forneceu base para o dia-a-dia das decisões relativas à gestão.

A estratégia deste geoparque tem uma visão global e baseia-se nos pontos fortes e oportunidades evidentes na região, além de propor uma estratégia de desenvolvimento sustentável em termos de posicionamento, desenvolvimento do mercado e suas melhorias, acesso aos aspectos geológicos, atrações vulcânicas e espeleológicas, juntamente com sinalizações e outras formas de garantia. A estrutura da administração do Geoparque Kanawinka tem como objetivo de formar parcerias no que diz respeito aos aspectos geológicos, patrimônio e a indústria do turismo, ao mesmo tempo proteger e promover a região como um geoparque global.

O planejamento estratégico deste geoparque conta com um plano de ação com todas as iniciativas a serem realizadas, determinando o tempo de execução e as quais ações já estão completas, assim como orçamento necessário e os indicadores chaves. Por meio do plano de gestão, o geoparque busca incentivar moradores e visitantes a experimentá-lo por meio de experiências artísticas de alta qualidade com base nos ativos geológicos da região. Para isso, o plano contém um cronograma de execução dessas ações determinando o tempo de execução, se ação está completa ou não e o orçamento necessário.

Em relação ao Geoturismo, o plano ressalta a criação de uma aliança estratégica para desenvolver e promover a atividade como um nicho de mercado, refletindo e realinhando o perfil dos visitantes. Na questão da Interpretação e Educação Ambiental o plano tem a visão de criar e promover oportunidades educacionais, formais e informais abrangendo todos os aspectos do geoparque para sua comunidade e os visitantes. No âmbito da geologia e paisagem o plano garante que os geossítios serão protegidos do desenvolvimento inadequado, com isso os responsáveis pela gestão do geoparque pretendem desenvolver políticas, inventários, base de dados como o intuito de promover um planejamento sustentável ao local. 


\subsection{Gestão do Geoparque Araripe (Ceará)}

Compreende o primeiro geoparque das Américas reconhecido pela Rede Global de Goeparques em 2006. Com relação a este geoparque, obteve-se o plano de trabalho que possui orientação para a elaboração do plano de gestão em que aborda a conceituação, organização do quadro de atividades dos vários setores do núcleo responsável pela gestão do Geoparque Araripe junto a URCA - Universidade Regional do Cariri de acordo com as recomendações da Rede Global de Geoparques e compromissos assumidos quando do credenciamento do mesmo na 2 a Conferência Internacional de Geoparque (em 2006), bem como as outras verificações.

A gestão deste geoparque pretende convalidar Diretrizes, Objetivos e Resultados que se referem às metas a serem alcançadas; atividades e normas relativas às ações que devem ser desenvolvidas, os requisitos básicos e necessários para atingir as metas estabelecidas seja financeira, material ou humana e por fim, a definição de prioridades a serem realizadas com o intuito de maximizar a gestão do Geoparque Araripe.

O objetivo do plano de gestão do Geoparque Araripe foi orientar a busca da qualidade da gestão durante o período de 2009 a 2012, assim como dimensionar um quadro de subsídios à elaboração de programas e planos de ação correlatos, bem como a seleção de indicativos para montagem do plano de manejo do geoparque. Vale salientar que neste caso, trata-se do plano para o Geoparque Araripe e não para as unidades de conservação existentes no território. Para essas unidades de conservação já existem seus planos de manejo, seguindo a legislação vigente (no caso o Sistema Nacional de Unidades de Conservação- SNUC).

O plano de gestão estabelecerá diretrizes para o desenvolvimento de uma cultura de autogestão e a implementação de processos de planejamento e avaliação baseados em verificações das consequências futuras de cada ação e dos processos relacionados. O plano também irá contribuir para a articulação e institucionalização das ações empreendidas pela URCA - Universidade Regional do Cariri, Governo do Estado do Ceará junto aos municípios que integram o geoparque, estimulando a participação da comunidade com o intuito de gerar benefícios coletivos.

A gestão do geoparque será fundamentada com a definição do Conselho Gestor e dos Setores Administrativo, responsável por viabilizar o funcionamento eficiente do geoparque; Infraestrutura e Manutenção, responsável infra-estrutura adequada e manutenção, conservação dos geossítios; Comunicações, responsável pela veiculação de informações do geoparque; Cooperação Institucional e Novos Projetos, responsável pela busca de apoio técnico, de fomento e financeiro ao geoparque. A gestão contará com Roteiros de Planos de Ação - Atividades em Arranjos Produtivos Locais/Alternativas de Desenvolvimento Sustentável/Educação Ambiental/Educação Patrimonial/Cooperação Internacional. 


\section{AVALIAÇÃO DOS MODELOS DE GESTÃO DOS GEOPARQUES NACIONAL E INTERNACIONAIS}

Como mencionado anteriormente, não existe uma lei que determine qual o tipo de gestão a ser seguido pelos geoparques, o que permite a estes diferentes formas de gerenciamento. Dentre os planos analisados, levando em conta sua construção como ferramenta gerencial, o plano de gestão do Geoparque Arouca é o mais completo entre os analisados, pois este abordar aspectos relevantes em um planejamento estratégico como Missão, Visão, Valores, Definição de Objetivos e Metas e Análise da Situação por meio da análise SWOT.

Em seu plano de gestão, o Geoparque Arouca contempla os aspectos de um planejamento estratégico em associação com o patrimônio geológico, o geoturismo e a importância social e econômica desta atividade para a comunidade. Por esta razão, o Geoparque Arouca teve a preocupação de fazer uma análise da situação por meio de uma ferramenta da administração (análise SWOT), evidenciando os pontos fortes e oportunidades bem como os pontos fracos e ameaças de uma forma geral no contexto do geoparque. Além do mais, o plano de gestão de Arouca contempla uma análise SWOT mais aprofundada, utilizando esta ferramenta em todos os segmentos que se encontram no território do Geoparque.

Diferente dos outros planos, Arouca ainda menciona em seu plano outra ferramenta da administração a Matriz de Enquadramento Lógico (MEL), abordando o objetivo geral, os específicos, atividades a serem realizados no geoparque, indicadores de realização e meios de verificação. Em conjunto com essas ferramentas (SWOT e MEL), o plano aborda estratégias de marketing, análise de mercado e sua segmentação, o significado da marca Arouca, avaliação e controle e instrumentos financeiros. Percebe-se como este plano é completo, não só por abordar as ferramentas administrativas, mas por fazer uma associação com os aspectos culturais, econômicos, patrimônio geológico, geoturismo. Além disso aborda dados referentes ao crescimento da população, faixa etária, qualificação da população e índice de envelhecimento, atividades referentes ao setor primário, secundário e terciários que são informações que os outros planos não abordam.

O plano de gestão do Geoparque Riviera apresenta uma estrutura de gestão bem integrada com o intuito de promover uma estratégia de geoconservação, para isso, este geoparque contém subcomitês com finalidades específicas que juntos garantem as diretrizes necessárias para o funcionamento do geoparque. Assim como o Geoparque Arouca este geoparque traz também a ferramenta da administração, análise SWOT, entretanto diferente daquele, este utiliza essa ferramenta direcionada exclusivamente nos aspectos geológicos do geoparque e não associa com os demais aspectos sociais, econômicos, turísticos e culturais. O plano do Geoparque Riviera descreve a importância do turismo para a região, a questão da degradação da vegetação, proteção costeira e defesa de inundação e a forma de eliminação dos resíduos. O plano relata que um dos pilares da sua gestão é o geoturismo, mas esta atividade no plano é tratada de maneira simples, sem maiores detalhamentos, ao contrário do Geoparque Arouca.

Outro plano avaliado foi o do Geoparque Stonehammer que contém uma estrutura de gestão diferente dos demais geoparques. A proposta de gestão deste, inclui uma estreita parceria 
com a filosofia de uma visão compartilhada. A elaboração do mesmo contou com a participação da comunidade, organizações e especialistas na área. O geoparque adotou este tipo de gestão por possuir mais de 60 geossítios e por estarem localizadas em áreas públicas e privadas, no qual o modelo de parceria facilitou a operacionalização do local. O plano demonstra a preocupação em detalhar as ações de cada parceiro que integra a estrutura de gestão do geoparque, abordando o posicionamento do Geoparque Stonehammer quanto ao cumprimento dos padrões científicos, condução sustentável e saudável do geoturismo, focando sua gestão na preservação e conservação, educação e conscientização, envolvimento local, envolvimento global e o desenvolvimento econômico e sustentável e geoturismo. O plano de gestão do Geoparque Stonehammer é bem completo e objetivo quanto ao cumprimento das ações. O que o difere do plano do Geoparque Arouca é a não utilização das ferramentas SWOT e MEL, o que não significa dizer que o plano do Stonehammer seja menos eficaz que o de Arouca, até porque cada plano foi desenvolvido para atender suas necessidades locais e gerenciais. Vale ressaltar que estes planos de gestão (Arouca e Stonehammer) foram os mais completos em detalhamento de informação, apesar do Arouca ter uma visão mais gerencial do geoparque por encará-lo como uma empresa e o Stonehammer mostra tudo o que acontece no geoparque e com seus parceiros.

O plano de gestão do Geoparque Kanawinka é um plano simples e bem objetivo, trazendo alguns elementos que constam em um planejamento estratégico como a visão do geoparque, os pontos fortes e oportunidades da região, porém não aborda os pontos fracos e ameaças, abrange as metas e objetivos e um plano de ação. O plano de gestão deste geoparque aponta objetivos gerais e específicos para fins do geoturismo, interpretação e educação ambiental, geologia e geoformas onde cada um destes possui um quadro mencionando as ações a serem executadas. A abordagem da gestão no plano de gestão do Geoparque Kanawinka não é tão aprofundada quanto aos outros, e sim o mais simples, não trás o detalhamento da área do geoparque e nem a composição da sua estrutura de gestão como os demais planos apresentam e nem ações que estão sendo desenvolvidas no geoparque.

Em relação a gestão do Geoparque Araripe, como mencionado anteriormente, obteve-se acesso apenas ao plano de trabalho do plano de gestão deste geoparque. Este plano ressalta a importância do plano de gestão para o andamento das atividades. Nele o geoparque deixa claro sua preocupação em abordar metas, objetivos, análise ambiental com o intuito de definir as ações a serem realizadas no geoparque. O plano de trabalho trás uma preocupação de inserir a comunidade no contexto do geoparque e transmitir a esta os resultados que se espera. Como este geoparque ainda passa por uma estruturação da sua gestão, a análise da sua gestão ficou limitada apenas ao plano de trabalho, onde o mesmo aponta as diretrizes a serem tomadas pelo geoparque, organização e dinâmica de sua gestão e a composição de sua estrutura.

A análise dos planos foi um passo necessário na pesquisa até mesmo para ter uma noção de como funciona o sistema de gestão de geoparques, já que um dos pré-requisito de qualquer proposta de geoparque seja aprovada é a criação de um sistema eficaz de gestão e a eficácia desse plano de gestão deve contemplar a comunidade e suas necessidades econômicas e culturais, com 
a finalidade de promover o desenvolvimento socioeconômico sustentável do território do qual está inserido.

O quadro 2 mostra um comparativo entre os diferentes geoparques analisados, apresentando os pontos em comum entre eles.

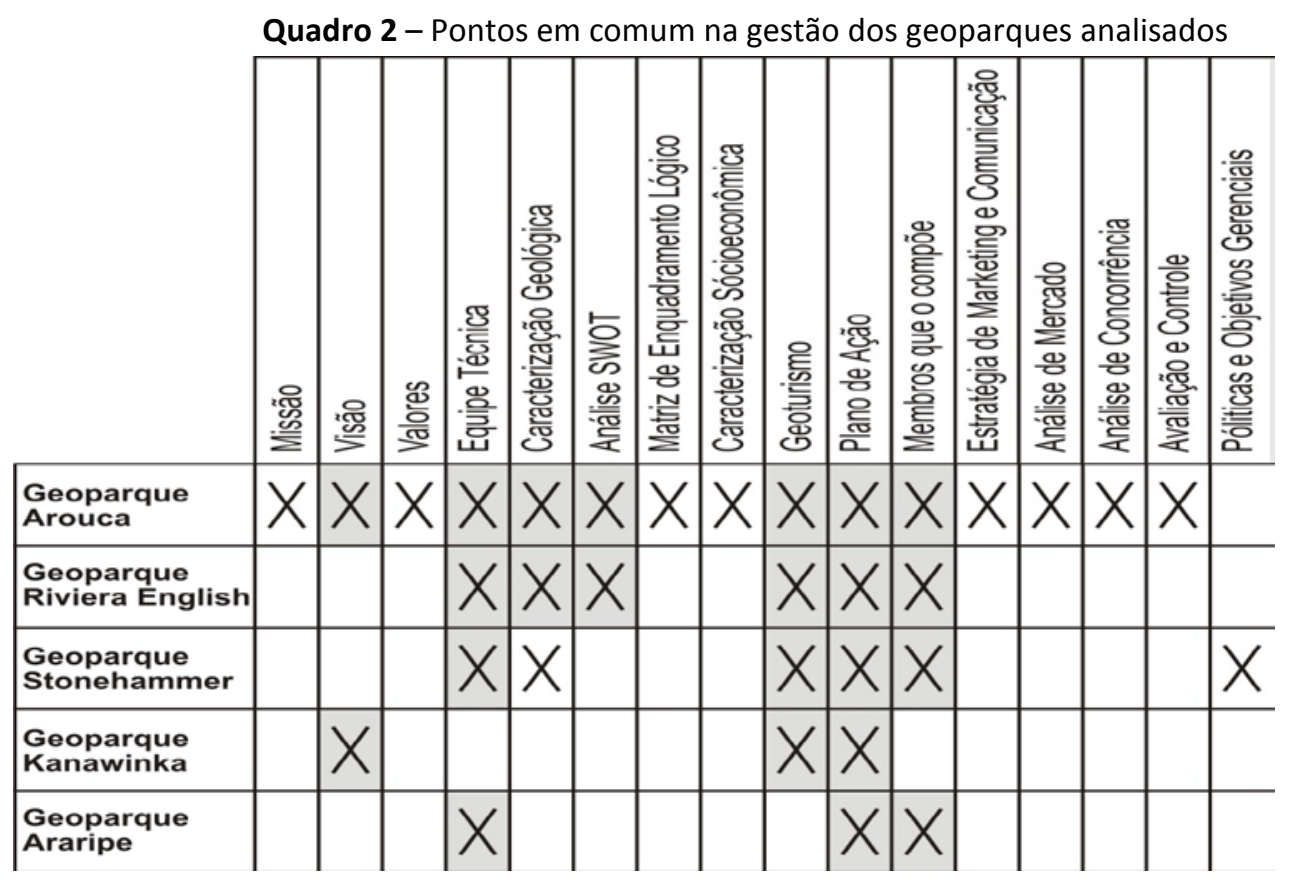

Fonte: Cardoso (2013)

Como o Brasil é detentor de inúmeros territórios propícios a geoparques (Moreira e Bigarella, 2010; Schobbenhaus e Silva, 2012; Nascimento et al., 2015), faz-se importante ter conhecimento a cerca de diferentes planos de gestão, para assim favorecer a criação de novos geoparques em território brasileiro. Lembrando que atualmente existe apenas um geoparque integrante na Rede Global de Geoparques - o Geoparque Araripe (CE).

Em razão da sua dinâmica e complexidade, como menciona Bacci et al. (2009), um geoparque pode ser adaptado a diferentes realidades, com diferentes formas de gestão, podendo até ser privado, além de serem fatores chaves para o desenvolvimento do Geoturismo, como afirmam Farsani et al. (2010), uma vez que maximizam esta atividade, além de proporcionar benefícios econômicos locais e educarem as pessoas sobre a evolução do local e sua paisagem.

O sucesso da gestão de um geoparque, como coloca Farsani et al. (2010), só pode ser conseguida através do envolvimento local forte, por esta razão, o plano de gestão deve ser estruturado com fins a contemplar a participação local, desenvolvimento econômico, educação, preservação e conservação, com diretrizes traçadas a chegar a este objetivo e a estruturação dessas questões dentro de um plano, objetivam e direcionam a operacionalização e funcionamento do geoparque, atingindo assim os objetivos propostos pela Rede Global de Geoparques e pela UNESCO.

Diante da importância do Geoturismo para o contexto de um Geoparque, até mesmo por esta atividade está ligada a outras modalidades de turismo (turismo de aventura, turismo cultural 
e ecoturismo) como colocado por Newsome e Dowling (2010), é interessante que o geoparque tenha um quadro de questão que contemple esta atividade, seus benefícios econômicos e principalmente a comunidade local.

\section{CONCLUSÃO}

O dinamismo de se adequar a diferentes realidades faz com que os Geoparques sejam visto como espaços que sirvam de apoio ao desenvolvimento econômico e social por meio do geoturismo. A não vinculação a uma lei específica os permite gerenciar seus espaços tanto no eixo governamental como na iniciativa privada. Por não apresentar um modelo padrão de gerenciamento desses espaços e com a finalidade de compreender a condução desses territórios, reuniram-se alguns planos de geoparque nacional e internacionais.

A gestão no aspecto dos geoparques ainda é um ponto pouco abordado no que se refere à produção científica, justamente por não haver um consenso para a sua aplicabilidade prática, visto as diferentes dinâmicas socioeconômicas e culturais de cada realidade local.

Estes planos permitiram visualizar que cada geoparque é administrado com base na realidade local de cada território e incorporação dos elementos socioeconômica na conjuntura do planejamento. Alguns geoparques utilizam ferramentas da administração para o gerenciamento dos recursos do geoparque, permitindo uma visão holística do meio e um caráter multidisciplinar.

Essa flexibilidade gerencial visualizada nos planos permite uma melhor adequação do planejamento com a realidade do local, além de articular grupos de trabalhos mais condizentes com os objetivos de cada território. Ademais, um sistema de eficaz gestão é um pilar importante por ser um pré-requisito para que qualquer proposta de Geoparque seja aprovada. Portanto a adoção de ferramentas da administração no gerenciamento desses espaços é de grande valia por permitir articular os eixos presentes em cada território e conseguir visualizar o espaço do ponto de vista da gestão com suas oportunidades e ameaças.

\section{REFERÊNCIAS}

AGA - Associação Geoparque Arouca. Plano Estratégico 2008-2013. (2008). Acesso outubro 20, 2012, em: <http://www.geoparquearouca.com/?p=geoparque\&sp=documentacao>.

Azevedo, Ú. R. (2007). Patrimônio Geológico e Geoconservação no Quadrilátero Ferrífero, Minas Gerais: Potencial para a Criação de um Geoparque da UNESCO. Tese de Doutorado. Universidade federal de minas gerais, Belo Horizonte.

Bacci. D.C., Piranha, J. M., Boggiani, P. C., DEL LAMA, E. A., \& Teixeira, W.(2009). GEOPARQUE - Estratégia de Geoconservação e Projetos Educacionais. Revista do Instituto de Geociências - USP. 5, 7-15.

Boggiani, P.C. (2010). A aplicação do conceito de Geoparque da UNESCO no Brasil e relação com o SNUC - Sistema Nacional de Unidades de Conservação. Revista Patrimônio Geológico e Cultura, 1(1): 1-4.

Cardoso, C.S. (2013). Geoparque Seridó: valores turísticos e gestão. Dissertação de mestrado, Universidade Federal do Rio Grande do Norte, Natal, RN, Brasil, 131p. 
Dossiê de Candidatura à Rede Mundial de Geoparks - UNESCO. Governo do Estado de Minas Gerais. Secretaria de Estado de Ciência, Tecnologia e Ensino Superior de Minas Gerais. (2009). Acesso julho 19, 2012 em: <http://www.geoparkquadrilatero.org/?pg=geopark\&id=168>.

Dowling, R.K. (2011). Geotourism's Global Growth. Geoheritage, 3:1-13.

Eder, F.W. \& Patzak, M. (2004). Geoparks-geological attractions: A tool for public education, recreation and sustainable economic development. Episodes, 27(3): 162-164.

Farsani, N. T. Coelho, C. \& Costa, C. (2011). Geotourism and Geoparks as Novel Strategies for Socio-economic Development in Rural Areas. International Journal of Tourism Research. 13 68-81

Farsani, N.T.; Coelho, C.; Costa, C. (2010). Geoparks as Art Museums for Geotourists. Revista Turismo e Desenvolvimento, 13: 173-182.

Hose, T. A. (2012). 3G's for Modern Geotourism. Geoheritage 4:7-24.

Kanawinka Geopark. Strategic Plan 2010-2012. Acesso julho 15, 2012 em: <http://www.kanawinkageopark.org.au/education/papers-and-publications/>.

Medeiros, R. (2006). Evolução das tipologias e Categorias de áreas protegidas no Brasil. Ambiente e Sociedade, 9(1) 42-64

Milano, M. (2001). Unidades de conservação - técnica, lei e ética para conservação da biodiversidade. In: Benjamin, A. (org.) Direito Ambiental das áreas protegidas. Rio de Janeiro: Forense.

Mochiutti, N.F., Guimarães, G.B., Moreira, J.C., Lima, F.F \& Freitas, F.I. (2012). Os Valores da Geodiversidade: Geossítios do Geopark Araripe/CE. Anuário do Instituto de Geociências - UFRJ, 35 (1), 173-189.

Moreira, J. C. (2011). Geoturismo e Interpretação Ambiental. Ponta Grossa: editora UEPG.

Moreira, J.C. \& Bigarella, J.J. (2010). Geotourism and Geoparks in Brazil. In: Dowling, R. \& Newsome, D. Global Geotourism Perspectives. London: Goodfellow Publishers Ltd., p. 137-152.

Moreira, J.C. (2011). Geoturismo e Interpretação Ambiental. Ponta Grossa: editora UEPG.

Nascimento, M. A. Ruchkys, U. A \& Neto, V. M. (2008). Geodiversidade, Geoconservação e Geoturismo: Trinômio Importante para a proteção do Patrimônio Geológico.

Nascimento, M.A., Gomes, C.S., \& Soares, A.S. (2015). Geoparque como forma de gestão territorial interdisciplinar apoiada no geoturismo: caso do Projeto Geoparque Seridó. Revista Brasileira de Ecoturismo, 8 (2), 347-364

Neves, J. L. (1996). Pesquisa Qualitativa- Características, Usos e Possibilidades. Caderno de Pesquisa em Administração.1 (3) 2으. sem.

Newsome D, Dowling RK (2010) Geotourism: the tourism of geology and landscape. Goodfellow Publishers, Oxford. Perinotto, A.R.C. (2009). Geoturismo: uma nova forma de atração turística - estudo de caso na alta Bacia do Rio Corumbataí, São Paulo, Brasil. Campinas, SeTur/SBE. Turismo e Paisagens Cársticas, 2(1), 27-39.

Schiefer, U. (2006). Manual de Planejamento e Avaliação de Projetos. 1o Ed.

Schobbenhaus, C. \& Silva, C.R. (2012). Geoparques do Brasil: propostas. Rio de Janeiro: CPRM.

Severino, A. J. (2007). Metodologia do Trabalho Científico. 23 ed, São Paulo: Cortez. 
Stonehammer geopark management plan. Acesso agosto 10, 2012 em: <http://www.stonehammergeopark.com/download-centre.html>.

The English Riviera Geopark Management Plan. (2007). Acesso Junho 10, 2012, em: <http://www.englishrivierageopark.org.uk/documents/geoparkmanplan.pdf>.

Zouros, N. (2004). The European Geopark network: Geological heritage protection and Local Development. Episodes 27:3, 165-171

Zouros, N. (2010). The European Geopark Network: Geological Heritage Protection and Local Development. Episodes, 27 (3) 165-171.

Zouros, N.C. (2007). Geomorphosite assessment and management in protected areas of Greece Case study of the Lesvos island - coastal geomorphosites. Geographica Helvetica, Jg. 62 2007/Heft 3.

Artigo recebido em: 14/10/2014. Artigo aprovado em: 13/08/2015. 